\title{
PENYULUHAN HUKUM INFORMASI DAN TRANSAKSI ELEKTRONIK BAGI PARA GURU DAN SISWA SDN 05 CEMPAKA BARU KEMAYORAN JAKARTA PUSAT
}

\author{
Endang Purwaningsih ${ }^{1)}$, Derta Rahmanto ${ }^{2)}$, Evie Rachmawati Nur Ariyanti ${ }^{3)}$ \\ ${ }^{1,2,3)}$ Sekolah Pascasarjana Universitas YARSI, Jakarta \\ email: e.purwaningsih@yarsi.ac.id
}

\begin{abstract}
Abstrak
Mengingat kesadaran hukum dan pengetahuan hukum guru dan siswa SDN 05 Cempaka Baru masih cukup rendah, dan sama sekali belum pernah mendapatkan penyuluhan hukum terkait informasi dan transaksi elektronik, maka perlu dilakukan upaya sosialisasi dan edukasi dalam upaya meningkatkan pengetahuan yang selanjutnya dapat menumbuhkan kesadaran hukum terkait informasi dan transaksi elektronik. Permasalahan mitra yang disikapi adalah bagaimana upaya sosialisasi regulasi dan edukasi dilakukan terhadap siswa dan guru SDN 05 Cempaka Baru guna meningkatkan pengetahuan hukum informasi dan transaksi elektronik. Kegiatan penyuluhan ini dikerjakan dengan ceramah dan tanya jawab dengan pemberian pre test dan post test, yang diselenggarakan bekerjasama dengan SDN 05 Cempaka Baru, Kemayoran Jakarta Pusat. Pelaksanaan kegiatan diikuti oleh guru dan siswa kelas V dan VI dan hasil penyuluhan menunjukkan peningkatan pengetahuan hukum informasi dan transaksi elektronik yang signifikan.
\end{abstract}

Kata Kunci : penyuluhan hukum, informasi dan transaksi elektronik, siswa, guru

\section{PENDAHULUAN}

Guru dan siswa di Sekolah Dasar sebagai subyek dan mitra pengabdian merupakan masyarakat terdidik, namun secara umum belum memperoleh pengetahuan maupun wawasan tentang hukum informasi dan transaksi elektronik. Sehari-hari mereka berkutat dengan materi pembelajaran yang mungkin saja tidak tersentuh teknologi informasi karena siswa dan guru di Sekolah Dasar sebagai subyek dan mitra pengabdian merupakan masyarakat umum yang belum memperoleh pengetahuan maupun wawasan tentang hukum informasi dan transaksi elektronik karena keterbatasan akses dan kurangnya waktu belajar. Di sisi lain telah muncul pelbagai kasus yang terjadi seperti pencemaran nama baik akibat keluhan yang diupload di media sosial yang kemudian berujung tuntutan, yang mungkin saja suatu saat nanti juga bisa menimpa warga sekolah. Untuk itu perlu diantisipasi dengan berbagai tindakan sosialisasi dan edukasi sebagai bekal warga sekolah utamanya dalam menatap dan menyongsong masa depan yang penuh dengan tantangan teknologi informasi, sebagai hal yang mau tidak mau harus disikapi bersama.

Kondisi warga sekolah SDN 05 Cempaka Baru sangatlah rentan terhadap informasi yang bersifat isu, mungkin hoax ataupun menipu, demikian pula posisi strategis sekolah ini terletak di Jakarta Pusat, sehingga dimungkinkan menjadi sasaran oknum yang bisa saja memanfaatkan situasi kondisi ketidaktahuan atau ketidakberdayaan warga sekolah menepis berita hoax ataupun pengaruh buruk dari informasi elektronik.

Untuk itulah perlu sosialisasi UU ITE berupa edukasi kepada warga sekolah agar membentengi dan membekali mereka sendiri akan aspek negatif dan positif informasi elektronik dalam kehidupan sehari-hari maupun pemanfaatannya demi masa depan.

Mengingat warga sekolah SDN 05 Cempaka Baru Kemayoran ini belum pernah memperoleh penyuluhan materi informasi elektronik ini, bisa dipahami jika pengetahuan mereka masih cukup rendah tentang informasi dan transaksi elektronik, tentu ada baiknya jika dilakukan penyuluhan hukum informasi dan transaksi elektronik, guna lebih mensosialisasikan dan meningkatkan pengetahuan dan kesadaran hukum warga sekolah utamanya siswa dan guru. Berdasarkan uraian di atas, maka dapat dirumuskan permasalahan mitra yang akan disikapi adalah bagaimanakah upaya sosialisasi regulasi dan edukasi dilakukan terhadap siswa dan guru SDN 05 Cempaka Baru guna meningkatkan 
pengetahuan hukum informasi dan transaksi elektronik?

\section{METODE KEGIATAN}

Kegiatan ini dilaksanakan dengan menggunakan metode-metode berikut.

1. Metode ceramah

Metode ini digunakan untuk menyampaikan materi penyuluhan yang bersifat kognitif namun dikemas dengan informasi yang menyenangkan mengingat siswa masih di bawah umur dan labil.

2. Metode Tanya Jawab

Dalam metode ini, kegiatan utama yang dilaksanakan adalah pembimbingan supaya berpola positive thinking dan memancing peserta untuk berani bertanya dan menyalurkan aspirasi.

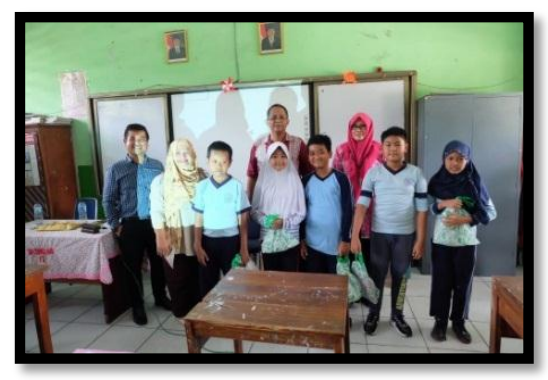

\section{HASIL DAN PEMBAHASAN}

Kegiatan dilaksanakan di SDN 05 Cempaka Baru Kemayoran Jakarta Pusat, diikuti oleh para guru dan siswa kelas V dan kelas VI, total berjumlah 109 orang

Tabel 1

Pemahaman tentang informasi dan transaksi elektronik

\begin{tabular}{|l|c|c|c|}
\hline & $\begin{array}{c}\text { Jawaban } \\
\text { responden }\end{array}$ & $\begin{array}{c}\text { Frequency } \\
\text { sebelum } \\
\text { penyuluhan }\end{array}$ & $\begin{array}{c}\text { Frequency } \\
\text { setelah } \\
\text { penyuluhan }\end{array}$ \\
\hline Valid & 1.00 & 43 & 3 \\
\cline { 2 - 4 } & 2.00 & 32 & 12 \\
\cline { 2 - 4 } & 3.00 & 22 & 20 \\
\cline { 2 - 4 } & 4.00 & 9 & 49 \\
\cline { 2 - 4 } & 5.00 & 3 & 25 \\
\cline { 2 - 4 } & Total & 109 & 109 \\
\hline
\end{tabular}

Pemahaman tentang informasi dan transaksi elektronik yang dirasakan oleh peserta penyuluhan dapat dijelaskan sebagai berikut. Ada sebanyak 25 orang yang sudah sangat memahami, sebanyak 49 orang sudah paham, dan sebanyak 20 orang sudah cukup paham. Sedangkan, sebanyak 15 orang masih kurang memahami keberadaan informasi dan transaksi elektronik.

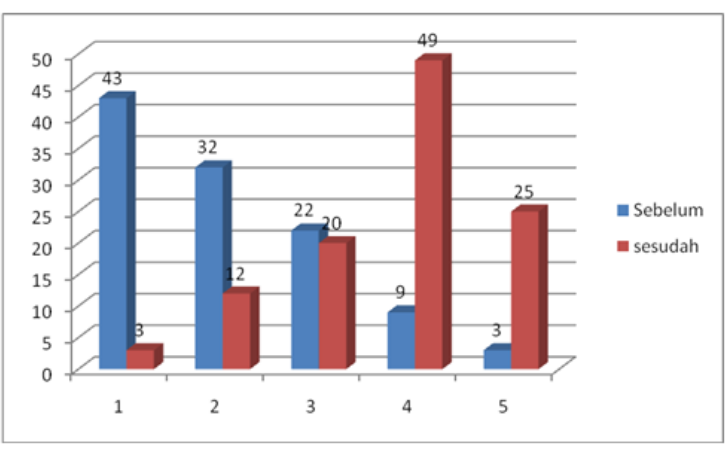

Diagram 1

Pemahaman tentang informasi dan transaksi elektronik

Tabel 2

Pemahaman tentang keuntungan penggUnaan ITE

\begin{tabular}{|c|c|c|c|}
\hline & $\begin{array}{c}\text { Jawaban } \\
\text { responden }\end{array}$ & $\begin{array}{c}\text { Frequency } \\
\text { sebelum } \\
\text { penyuluhan }\end{array}$ & $\begin{array}{c}\text { Frequency setelah } \\
\text { penyuluhan }\end{array}$ \\
\hline \multirow{7}{*}{ Valid } & 1.00 & 37 & 2 \\
\cline { 2 - 4 } & 2.00 & 34 & 11 \\
\cline { 2 - 4 } & 3.00 & 22 & 18 \\
\cline { 2 - 4 } & 4.00 & 10 & 52 \\
\cline { 2 - 4 } & 5.00 & 6 & 26 \\
\cline { 2 - 4 } & Total & 109 & 109 \\
\hline
\end{tabular}

Berdasarkan tabel hasil penyuluhan sebagaimana tersebut di atas, dapat dipahami bahwa sudah ada sebanyak 26 orang yang sudah sangat paham tentang keuntungan pengganaan ITE. Ada sebanyak 52 orang yang sudah paham, dan sebanyak 18 orang sudah cukup paham tentang penggunaan ITE. Hanya saja masih ada sebanyak 13 orang yang belum paham tentang keuntungan penggunaan ITE

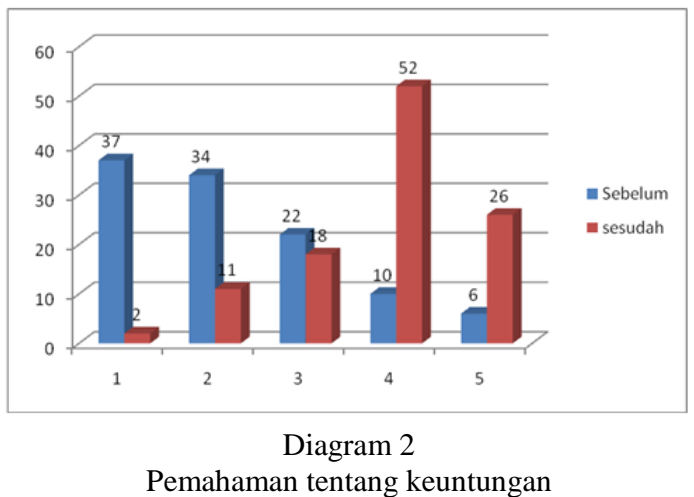

Pemahaman tentang keuntungan penggunaan ITE 
Tabel 3

Faktor Negatif Penggunaan ITE

\begin{tabular}{|c|c|c|c|}
\hline \multirow{7}{*}{$\begin{array}{c}\text { Jawaban } \\
\text { responden }\end{array}$} & $\begin{array}{c}\text { Frequency sebelum } \\
\text { penyuluhan }\end{array}$ & $\begin{array}{c}\text { Frequency } \\
\text { setelah } \\
\text { penyuluhan }\end{array}$ \\
\hline \multirow{7}{*}{ Valid } & 1.00 & 39 & 9 \\
\cline { 2 - 4 } & 2.00 & 33 & 13 \\
\cline { 2 - 4 } & 3.00 & 22 & 18 \\
\cline { 2 - 4 } & 4.00 & 11 & 30 \\
\cline { 2 - 4 } & 5.00 & 4 & 109 \\
\cline { 2 - 4 } & Total & 109 & 39 \\
\hline
\end{tabular}

Tabel di atas memberikan informasi bahwa pemahaman peserta penyuluhan, mayoritas sudah memahami berbagai faktor negatif (kelemahan) penggunaan ITE. Terbukti, ada sebanyak 39 orang yang sudah sangat paham tentang faktor negatif penggunaan ITE, ada sebanyak 30 roang yang sudah paham, dan ada 18 orang yang sudah cukup paham. Sisanya, memang masih ada sebanyak 21 orang yang belum paham berbagai faktor negatif penggunaan ITE.

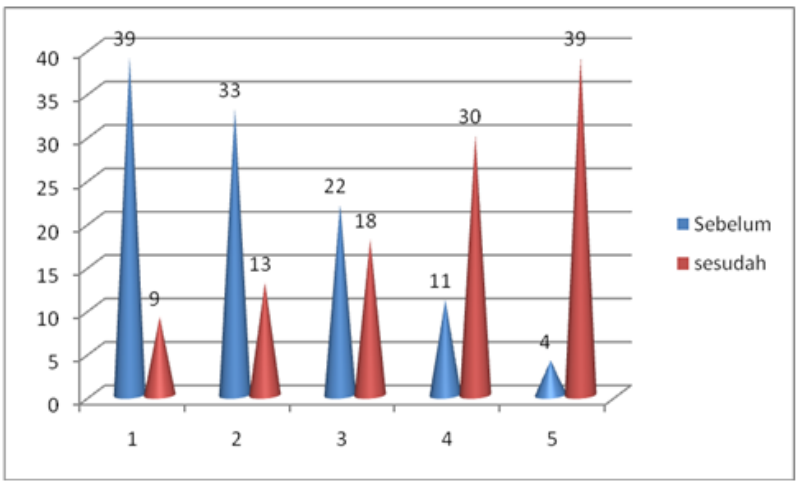

Diagram 3

Faktor Negatif Penggunaan ITE

Tabel 4.

Pemahaman tentang berbagai cara bermedsos dan bertransaksi on-line agar terlindungi hukum

\begin{tabular}{|c|c|c|c|}
\hline \multirow{4}{*}{} & $\begin{array}{c}\text { Jawaban } \\
\text { responden }\end{array}$ & $\begin{array}{c}\text { Frequency } \\
\text { sebelum } \\
\text { penyuluhan }\end{array}$ & $\begin{array}{c}\text { Frequency setelah } \\
\text { penyuluhan }\end{array}$ \\
\hline \multirow{4}{*}{ Valid } & 1.00 & 44 & 4 \\
\cline { 2 - 4 } & 2.00 & 23 & 13 \\
\cline { 2 - 4 } & 3.00 & 22 & 22 \\
\cline { 2 - 4 } & 4.00 & 7 & 33 \\
\cline { 2 - 4 } & 5.00 & 3 & 37 \\
\cline { 2 - 4 } & Total & 109 & 109 \\
\hline
\end{tabular}

Berdasarkan tabel di atas dapat diketahui bahwa ada sebanyak 37 orang yang sudah sangat paham tentang berbagai cara bermedsos dan bertransaksi on-line agar terlindungi hukum. Ada sebanyak 33 orang yang sudah paham, dan sebanyak 22 orang sudah cukup paham. Sisanya, masih ada sebanyak 17 orang yang belum paham tentang berbagai cara bermedsos dan bertransaksi on-line agar terlindungi hukum.

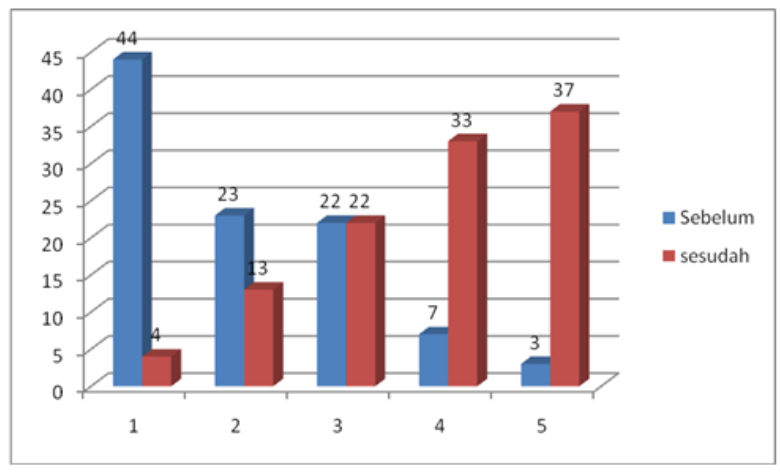

Diagram 4

Pemahaman tentang berbagai cara bermedsos dan bertransaksi on-line agar terlindungi hukum

Tabel 5.

Pemahaman perlunya pendampingan dan Pengawasan orang tua dan guru dalam memanfaatkan medsos.

\begin{tabular}{|c|c|c|c|}
\hline & $\begin{array}{c}\text { Jawaban } \\
\text { responden }\end{array}$ & $\begin{array}{c}\text { Frequency } \\
\text { sebelum } \\
\text { penyuluhan }\end{array}$ & $\begin{array}{c}\text { Frequency } \\
\text { setelah } \\
\text { penyuluhan }\end{array}$ \\
\hline \multirow{5}{*}{ Valid } & 1.00 & 40 & 3 \\
\cline { 2 - 4 } & 2.00 & 35 & 7 \\
\cline { 2 - 4 } & 3.00 & 21 & 21 \\
\cline { 2 - 4 } & 4.00 & 9 & 34 \\
\cline { 2 - 4 } & 5.00 & 4 & 44 \\
\cline { 2 - 4 } & Total & 109 & 109 \\
\hline
\end{tabular}

Tabel di atas memberikan informasi bahwa pemahaman perlunya pendampingan dan Pengawasan orang tua dan guru dalam memanfaatkan medsos sudah sangat baik. Terbukti, ada sebanyak 44 orang yang sudah dangat paham, sebanyak 34 orang sudah paham, dan 21 orang sudah cukup paham. Sisanya sebanyak 10 orang belum memahami. Untuk lebih jelasnya dapat dilihat diagram berikut. 


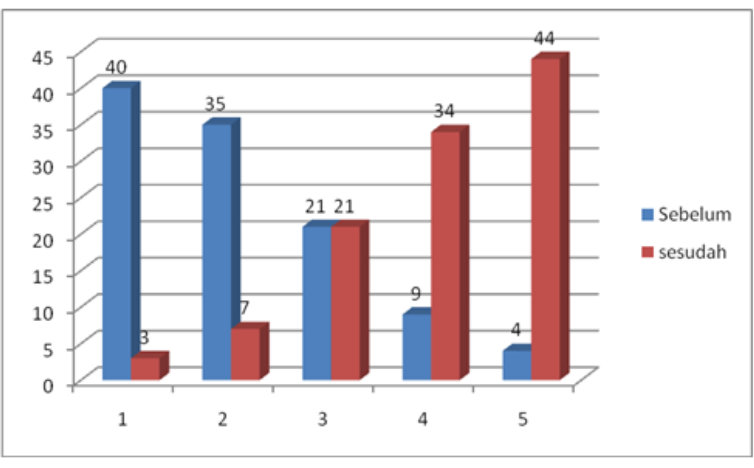

Diagram 5.

Pemahaman perlunya pendampingan dan Pengawasan orang tua dan guru dalam memanfaatkan medsos.

\section{KESIMPULAN DAN SARAN}

\subsection{Kesimpulan}

Penyuluhan hukum perlu dilakukan tidak hanya sekali saja, namun perlu terus dibangun dan ditingkatkan secara periodik seiring dengan dinamika perkembangan hukum dan kebutuhan masyarakat, dalam hal ini terkait guru dan siswa. Sosialisasi regulasi dan edukasi mampu meningkatkan pengetahuan dan tingkat kesadaran hukum, khususnya dalam kegiatan penyuluhan hukum informasi dan transaksi elektronik bagi para Guru dan Siswa SDN 05 Cempaka Baru Kemayoran Jakarta Pusat.

\subsection{Saran}

Perlu peran aktif guru dan orangtua serta perguruan tinggi untuk membantu para siswa memahami transaksi agar terlindungi oleh hukum, dengan menularkan pengetahuan melalui kegiatan pengabdian kepada masyarakat.

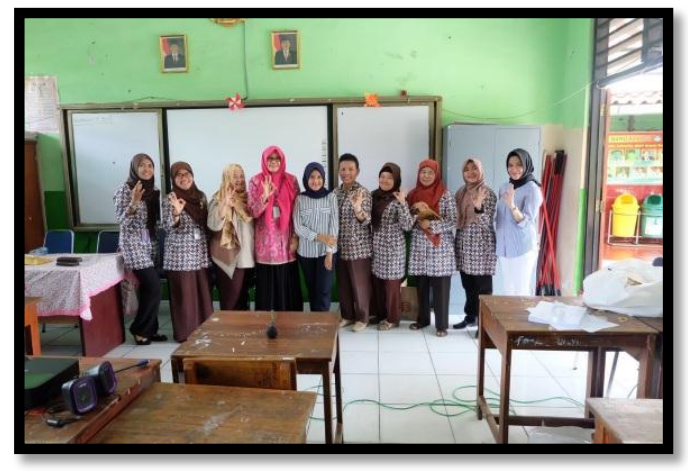

\section{REFERENSI}

Koswara, Engkos. 2009.Legalisasi Software melalui Open Source, dalam buku Sains dan Teknologi2, Ristek, Jakarta: Gramedia Pustaka Utama

Makarim, Edmon.2010. Tanggungjawab Hukum Penyelenggara Sistem Elektronik, Bandung: Rajagrafindo

Prihatman, Kemal. 2009.Wimax dan Peluang Industri dalam Negeri, dalam buku Sains dan Teknologi2, Ristek, Jakarta: Gramedia Pustaka Utama

Purwaningsih, Endang. 2009, Hukum Bisnis, Jakarta: Ghalia Yudistira

Salman, Otje dan Anton F. Susanto.2006. Teori Hukum, Bandung: Refika Aditama

UU Nomor 19 tahun 2016 tentang Perubahan atas Undang-Undang nomor 11 tahun 2008 tentang Informasi dan Transaksi Elektronik jo.UndangUndang Nomor 11 Tahun 2008 tentang Informasi dan Transaksi Elektronik 